\title{
Measurement of space and motion discomfort in persons with vestibular disorders
}

\author{
Susan L. Whitney ${ }^{1 *}$, Gergory F. Marchetti ${ }^{2}$, Rolf G. Jacob ${ }^{3}$ and Joseph M. Furman ${ }^{4}$
}

*Correspondence: whitney@pitt.edu

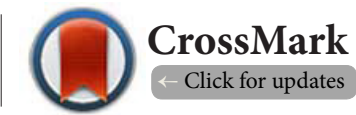

'Professor- University of Pittsburgh, Department of Physical Therapy, USA.

${ }^{2}$ Associate Professor, Duguesne University, Department of Physical Therapy, USA.

${ }^{3}$ Professor, Universtiy of Pittsburgh, Department of Psychaitry, USA.

${ }^{4}$ Professor, Universtiy of Pittsburgh, Department of Otolaryngology, USA.

\begin{abstract}
Background: The purpose of this paper was to estimate the test-retest agreement and to describe the discriminative validity of measures recorded from the Situational Characteristics Questionnaire-extended (SitQe) for the identification of space and motion discomfort in subjects with balance/vestibular disorders in comparison to healthy control subjects.

Methods: A cross-sectional descriptive study was conducted with eighty-nine patients with balance and/or vestibular disorders and 44 control subjects. All patients completed the SitQe at a tertiary care ambulatory out-patient balance and vestibular clinic. Test-retest agreement for individual SitQe items was tested in a subsample of fifteen people with balance/vestibular disorders and 20 control subjects. The SitQe consists of 105 questions. A $\chi^{2}$ analysis was used to determine if there were differences in response rates indicative of discomfort for patients versus control subjects. Data were made categorical and compared between no symptoms while performing the activity versus mild or worse symptoms during the activity.

Results: Median test-retest agreement at the item level was good to excellent across all related situational categories. Seventy-six out of 105 variables were significantly different between the control subjects and patients with balance and/or vestibular disorders at $\mathrm{p}<0.01$.

Conclusion: Patients with vestibular disorders reported symptoms for many of the daily life activities during which the control group had few, if any, symptoms. These items may provide the clinician with some insight into which activity (ies) might be difficult for a person living with a balance and/or vestibular disorder. Clinicians might want to consider probing more about common activities that can provoke dizziness in order to better target interventions.
\end{abstract}

Keywords: Dizzines, vestibular, rehabilitation, outcomes, motion sensitivity

\section{Introduction}

Persons with vestibular deficits often develop an over reliance on visual inputs, resulting in visual dependence [1]. When patients over rely on visual input, balance can be affected. Patients may not use other available sensory inputs for postural control, and situationally provoked dizziness may result as a consequence [1].

Psychologic factors appear to influence how people respond to and perceive situational dizziness $[2,3]$. Staab and Ruckenstein [4] have suggested that persons with vestibular disorders may develop mild situational phobias because of their fear of developing dizziness. They suggest that some patients may avoid certain situations that the perceive may provoke their dizziness.

Situational dizziness has been shown to be a negative predictor for return to full function in persons with vestibular disorders [5-8]. "Space and motion discomfort" (SMD) was chosen for use throughout this paper to describe dizziness that is provoked by visually provocative situations (i.e. grocery stores, malls, ceiling fans) [9]. The clinical recognition of SMD and its effects on patient outcome may be an important and under-recognized element of patient management.

There are a few instruments in the literature that include items that attempt to quantify SMD in persons with balance 
Whitney et al, Physical Therapy and Rehabilitation 2018,

and vestibular disorders [10-14]. The instruments currently in use that quantify aspects of SMD include the Vertigo Symptom Scale (VSS) [13], the Vertigo Handicap Questionnaire (VHQ) [14], the Vestibular Activities of Daily Living Scale (VADL) $[12,15]$, and the Vestibular Rehabilitation Benefit Questionnaire (VRBQ) $[10,11]$. The VSS includes feelings of disorientation [13], the VHQ and the VADL include an item related to having difficulty in a grocery store $[12,13,15]$, the VSS has a visual disturbance item [13], the VRBQ includes items such as having difficulty traveling and avoiding situations that previously did not cause symptoms $[10,11]$. A comprehensive tool that describes the range of potential provocative stimuli that can provoke SMD in patients with vestibular and balance disorders is not commonly used clinically.

A previously developed questionnaire was modified to attempt to capture how people perceive their SMD [9]. The original motivation for the development of the Situational Characteristic Questionnaire (Sit Q) was to determine if various situations caused discomfort in people with anxiety disorders [9]. In patients with anxiety disorders, SMD was associated with balance abnormalities [16,17]. Furthermore, high levels of SMD were found in patients with vestibular disorders as compared to patients with hearing loss [9].

The Situational Characteristics Questionnaire-extended (SitQe) was developed to attempt to include additional vestibular items that patients commonly report as problems. Twenty new items were generated and added to the SitQe based on the clinical experience of three of the authors with over 80 years of combined experience with people with balance/vestibular disorders. The SitQe has been used as an outcome measure previously in persons with uncompenstated peripheral vestibular disorders [8]. After physical therapy intervention, Pavlou et al noted a $75 \%$ decrease in symptoms in a grocery store after intervention [8]. The SitQe used by Pavlou et al [8] was able to identify change over time in patients with vestibular disorders. The SitQe in the Pavlou paper was used to assess SMD over time from physical therapy interventions, yet the reliability and validity of the instrument had not been reported.

Presently, there is no specific self-report tool to describe SMD in patients with balance/vestibular disorders. Space and motion symptoms may affect rehabilitation outcomes in persons with vestibular disorders. Therefore, it is important for clinicians to be able to recognize these symptoms as they may commonly manifest in patients with vestibular disorders. The purpose of this study was twofold: 1) to estimate the test-retest agreement for individual SitQe items in persons with balance/vestibular disorders and 2) to describe the known-groups validity of measures recorded from the SitQe to identify SMD in subjects with balance/vestibular disorders in comparison to healthy control subjects. This study is a first step in the development of a clinically feasible tool to measure SMD in persons with vestibular dysfunction.

\section{Methods}

\section{Participants}

The data of eighty-nine vestibular patients who had completed the SitQe were examined and compared with data collected on 44 normal control subjects who had participated in other research studies in our laboratory. The study was approved by the Biomedical Institutional Review Board of the University of Pittsburgh. Twenty-four of the control subjects had normal test results including calorics, positional testing, oculomotor exam and rotational chair testing. The remaining 20 control subjects had no complaints of dizziness or balance problems for entry into the study.

Data on control subjects were obtained from research records established because of their participation in this study and other past and ongoing research studies. The patients were diagnosed clinically, aided by the vestibular laboratory tests of a tertiary University ENT clinic. Patient diagnoses were established by a neurologist who specializes in otology with over 30 years of specialty practice experience. All patients seen by the neurologist had undergone vestibular testing (calorics, positional testing, oculomotor exam, and rotational chair testing) and were diagnosed with vestibular or balance dysfunction.

Patient diagnoses included: BPPV $(n=26)$, unspecified dizziness ( $n=19)$, unilateral hypofunction (18), disequilibrium of aging $(n=8)$, central vestibular dizziness $(n=6)$, Ménière's $(n=3)$, migraine-related dizziness ( $n=3)$, labyrinthine concussion $(n=2)$, mal de debarquement $(n=2)$, bilateral hypofunction $(n=1)$, and cervicogenic dizziness $(n=1)$. Those with unspecified dizziness $(n=19)$ had borderline abnormal vestibular test results and the physician was unable to specify a definitive vestibular diagnostic designation.

Patients with balance and vestibular disorders were sent the questionnaire in the mail and were asked to bring the form completed to the clinic. No instructions other than the instructions on the form were provided. Participants were permitted to leave blank up to $20 \%$ of the items for the questionnaire to be considered complete. For example, not all people had experienced buses or airplanes after their vestibular event, and therefore did not complete those items.

The questionnaire takes approximately $5-10$ minutes to complete, depending on the persons reading abilities. The physical therapist reviewed the completed SitQe upon patient arrival, which were then scanned and scored.

\section{Instrument: The SitQe}

The SitQe is an expansion of the original Sit $Q$ and was administered as a paper and pencil test without concomitant interviews or review and pursuit of missing responses. For the original SitQ, reliability and validity data were published in Jacob, Woody et al [9]. Reliability ranged from $r=0.66-0.87$ for the different categorical sections of the instrument; Cronbach's alpha varied between $0.67-0.88$. To establish test-retest agreement for the individual items, the SitQe was administered to 
a sub-sample of 35 persons ( 15 with vestibular disorders, 20 without) on two occasions across a time interval of 3 days to one week.

\section{The instructions for the SITQe are:}

"Below are some situations that may elicit discomfort or anxiety for you. We are interested in whether certain characteristics of the situation bother you in comparison with other characteristics of the same situation. Please circle:

3 If you are very much bothered by the characteristic

2 If you are moderately bothered by the characteristic

1 If you are mildly bothered by the characteristic

0 If you are not bothered by the characteristic"

The additional 20 Likert items that were added to create the SitQe were based on the clinical experience of a physical therapist and two physicians who has worked with patients with vestibular disorders with a combined work experience with persons with vestibular disorders of 95 years. The instructions were:

"Are you bothered by any of the following:

3 Very bothered

2 Moderately bothered

1 Mildly bothered

0 Not bothered"

In the SitQe, the item response was coded binarily as either "discomfort absent," if the participant circled " 0 ," or "present," for responses 1-3 above.

\section{Data analysis}

The frequency count of responses signifying "discomfort present" was determined separately for control subjects and patients. Test-retest agreement for presence of discomfort for each SitQe item across two administrations to the subsample was estimated using Cohen's kappa statistic. The median kappa value and corresponding inter-quartile range was reported across categories of SitQe items (car, bus, supermarket and others).

To examine the association between the report of discomfort and the presence of vestibular disorders, a chi-squared analysis with Yates correction of the resulting $2 \times 2$ table was used for each item to determine statistical group differences. Because the analyses involved multiple comparisons, target significance level was set at $p<0.01$. Group differences in the frequency of subjects reporting discomfort associated with each item were described as proportional differences in reports of discomfort and using the arcsine transformation and effect size index as described by Cohen [18]. Proportional differences are ineffective effect size measures because the variance and the power to detect a true difference in proportions are dependent on the location of the proportions on the binomial scale of zero to 1 . The effect size index (h) derived from the arcsin transformation of proportions provides a uniform indicator of the proportional difference in discomfort between groups that is not subject to the variance difference due to the contributing proportion values. The effect size index (h) derived from the transformation of proportions can range from 0 (no proportional difference) to 3.14 (100\% difference).

\section{Results}

Mean age of the control group was $43 \pm 17$ years (range 22-83). The gender distribution was 28 females (64\%) and $16(36 \%)$ males. The mean age of the patients was $59 \pm 18$ (range 22-89). The gender distribution was 60 females (67\%) and 29 males. Test-retest agreement of individual items. Test-retest agreement across 3 days to 1 -week testing intervals for SitQe items in situational categories was good to excellent in 35 subjects (15 with vestibular disorders and 20 without). Median kappa statistics for estimates of test-retest agreement ranged from 0.69 for using escalators ( 6 items) to 0.89 for activities performed while taking a shower ( 2 items). Table 1 presets the median and inter-quartile range kappa agreement estimates across categories of SitQe items.

Table 1. Test re-test agreement for Situational Characteristic Questionnaire extended (SitQe) Categories: Median Kappa ratings of agreement, number of items and agreement interquartile range across categories.

\begin{tabular}{llll}
\hline Category & $\begin{array}{l}\text { Number } \\
\text { of Items }\end{array}$ & $\begin{array}{l}\text { Median } \\
\text { Kappa }\end{array}$ & $\begin{array}{l}\text { Inter-quartile } \\
\text { Range }\end{array}$ \\
\hline Riding in car as passenger & 16 & 0.80 & $0.70-0.89$ \\
Buses & 8 & 0.73 & $0.64-0.80$ \\
Supermarkets & 6 & 0.78 & $0.76-0.89$ \\
Large fields or open squares & 4 & 0.80 & $0.71-0.90$ \\
Tunnels & 4 & 0.87 & $0.86-0.90$ \\
Movie Theaters & 6 & 0.75 & $0.63-0.79$ \\
Airplanes & 9 & 0.80 & $0.7-0.88$ \\
Elevators & 13 & 0.81 & $0.73-0.88$ \\
Escalators & 6 & 0.69 & $0.66-0.75$ \\
Going up stairways & 2 & 0.72 & $0.60-0.83$ \\
Driving a car & 5 & 0.79 & $0.68-0.87$ \\
Walking & 4 & 0.70 & $0.66-0.75$ \\
In a shower & 2 & 0.89 & $0.87-0.91$ \\
Mobility and ADL items $\dagger$ & 20 & 0.74 & $0.61-0.88$ \\
\hline
\end{tabular}

$\dagger$ The difference between the original Sit-Q and the SitQe is the addition of 20 Likert items that include mobility and ADL items.

Association between items reported as provoking discomfort and subject group. The median percent of non-responses to items from all subjects was $8 \%$ ( 8 items). Among individual items, airplane (25\%), bus (22\%), aerobics (21\%), and dancing $(18 \%)$ items had the greatest non-response rates for all subjects. Non responses for the control subjects were negligible. In control subjects, 16 items displayed non-responses. The maximum number of non-responses for any item was $2(5 \%)$, which was observed on two of the elevator items. In subjects with vestibular disorders, the median percent of non-responses was $11 \%$ (12 items). The greatest percent of non-responses 
Whitney et al, Physical Therapy and Rehabilitation 2018,

http://www.hoajonline.com/journals/pdf/2055-2386-5-18.pdf

doi: 10.7243/2055-2386-5-18

to individual items in persons with vestibular disorders was seen for the various airplane items (range 34-37\%).

Seventy-six of the 105 SitQe items (72\%) demonstrated a significant association (at $p<0.01$ ) between symptom provocation and vestibular disorders. The average effect size for the difference between the proportion of healthy subjects and subjects with a vestibular disorder who reported symptoms was 0.93 for items with a significant association between symptom report and subject group. The greatest effect size of difference in the proportion of subjects in each group reporting situational discomfort was observed in the group of mobility and ADL items.

Tables 2-4 present the differences between persons with balance and vestibular disorders and healthy controls in perception of SMD. The item results have been categorically reduced for ease of interpretation in Tables 2-4 compared to the order within the SitQe. In the SitQe, the categories (i.e. riding as a passenger in a car, buses, supermarkets, etc.) are ordered in a manner to prevent carryover of responses from one category to another. Table 2 presents the proportion and effect size of difference for subjects in both groups reporting discomfort associated with transportation-related situations. The average significant difference in the proportion of group members reporting discomfort was $26 \%$ (effect size 0.72 ) across the transportation items with a significant association between discomfort and subject group. The group differences in proportion of subjects reporting on these items ranged from $17 \%$ ("riding on an empty bus") to $48 \%$ ("looking out window while traveling in a car").

The proportion of subjects in both groups reporting discomfort and the effect size difference with environmental/ architectural/activity situations are shown in Table 3 . The average proportional group difference for environmental/ architectural/activity items with a significant association between report of discomfort and subject group was 31\% (effect size 0.72), ranging from $17 \%$ ("riding and empty elevator"/"sitting in theatre in aisle seat") to 64\% ("walking down corridor looking to side").

Table 4 presents the proportional differences and effects sizes between persons with vestibular disorders and control subjects on SitQe mobility and ADL items. The average proportional difference between vestibular and control subjects on mobility and ADL items with a significant discomfort-subject group association was $45 \%$ (effect size 1.16), ranging from $15 \%$ ("looking in mirror"/"lying in bed") to $73 \%$ ("picking up item from floor").

\section{Discussion}

The SitQe items appear to have good to excellent test-retest agreement in a mixed group of people with balance and vestibular disorders, suggesting that the tool is repeatable [18]. The results describe a range of commonly encountered situations that provoke SMD more frequently in patients with balance and vestibular disorders compared with healthy subjects. Seventy-six of the 105 items (72\%) supported different responses between patient and control subject groups. Many of the items on the SitQe can effectively discriminate the perception of SMD in persons with balance and vestibular disorders from healthy subjects.

The investigators were not suggesting that clinicians should use a 105-item questionnaire but were suggesting that items that might increase symptoms should be included. Later work will shorten the tool to make it more clinically feasible for use in patient practice settings.

This study was conducted in an urban setting with a mixture of urban and suburban subjects. It is impossible to determine if patients or control subjects are avoiding or are simply not exposed to the situations that were probed in the SitQe. Of the 36 transportation items, 20 were different between subject groups with car items ( $57 \%$ of the 21 car items) having the greatest number of differences between groups. Many of the subjects had access to private transportation, which may have affected the results. It is not clear if the differences noted were because people avoid other forms of transportation or whether riding in a car is extremely difficult. Page and Gresty [19] have reported several cases of persons with vestibular disorders having increased difficultly with driving. Murray et al [20] reported that $1 / 3$ of their patients with unilateral hypofunction had difficulty with driving, climbing ladders, and concentrating.

Airplane questions do not appear to be particularly discriminative between people with and without vestibular disorders. Sitting on the airplane aisle was the only question that was different between patient and control subjects, suggesting that vestibular dysfunction alone does not increase people's sensitivity to air flight. Twenty-five percent of the total number of respondents did not complete the airplane items. One possible explanation is that there is less exposure to airplane travel and thus there was no basis on which to describe their discomfort. Another potential explanation is that the patients may have had changes in their perceptions because of their vestibular/balance disorders and appeared to be less sure of how they would feel on a bus or in an airplane compared to control subjects. Patients may not have been exposed to air travel since their diagnosis and there is no option for "not applicable" on the questionnaire. In addition, socio-economic factors may have confounded the likelihood of a non-response on airplane items as air travel is more common in upper socio-economic demographics. Reasons for non-responses on the questionnaire should be investigated but was beyond the scope of this study.

The only mobility/ADL item that was not significant between the control and vestibular subjects was "sitting". All other mobility items were more bothersome to persons living with vestibular disorders than control subjects. These data suggest that many normal activities that one performs daily cause discomfort performing the activity. Rolling over in bed, showering, reading, watching a fast action television 
Whitney et al, Physical Therapy and Rehabilitation 2018,

http://www.hoajonline.com/journals/pdf/2055-2386-5-18.pdf

Table 2. Transportation items: Proportion of persons reporting being at least mildly bothered (89 patients and 44 control subjects) with group proportion differences and effect sizes (h) for differences.

\begin{tabular}{|c|c|c|c|c|}
\hline Item & Patient (\%) & Control (\%) & Proportional Difference & h \\
\hline Car Uphill & 34 & 5 & 29 & $0.79^{\star}$ \\
\hline Car Downhill & 38 & 14 & 24 & $0.57^{\star}$ \\
\hline Car Bumpy Road & 47 & 27 & 20 & 0.42 \\
\hline Car Smooth Road & 20 & 2 & 18 & $0.65^{\star}$ \\
\hline Car Straight Road & 23 & 2 & 21 & $0.70^{\star}$ \\
\hline Car Winding Road & 58 & 33 & 25 & $0.51^{\star}$ \\
\hline Car Wide Road & 22 & 0 & 22 & $0.96^{*}$ \\
\hline Car Narrow Road & 41 & 26 & 15 & 0.31 \\
\hline Car on limited access road & 30 & 9 & 21 & $0.55^{\star}$ \\
\hline Car unlimited access road & 27 & 0 & 27 & $1.08^{*}$ \\
\hline Car riding in front seat & 31 & 7 & 24 & $0.64^{*}$ \\
\hline Car riding in back seat & 48 & 27 & 21 & 0.44 \\
\hline Car Change Speed & 50 & 18 & 32 & 0.69 \\
\hline Car riding at steady speed & 19 & 0 & 19 & 0.90 \\
\hline Car Reading & 68 & 36 & 32 & $0.64^{\star}$ \\
\hline Car Window & 48 & 0 & 48 & $1.52^{\star}$ \\
\hline Drive wipers off & 10 & 0 & 10 & 0.64 \\
\hline Drive wipers on & 23 & 2 & 21 & $0.72^{\star}$ \\
\hline Drive no shade & 11 & 0 & 11 & 0.68 \\
\hline Drive partial shade & 26 & 11 & 15 & 0.39 \\
\hline Drive complete shade & 13 & 0 & 13 & 0.74 \\
\hline Bus standing platform & 56 & 23 & 33 & $0.68^{*}$ \\
\hline Bus sit & 23 & 2 & 21 & $0.72^{*}$ \\
\hline Bus sitting on aisle & 23 & 9 & 14 & 0.38 \\
\hline Bus sitting by window & 23 & 7 & 16 & 0.47 \\
\hline Bus still & 31 & 7 & 24 & $0.65^{*}$ \\
\hline Bus moving & 41 & 16 & 25 & $0.57^{*}$ \\
\hline Bus crowded & 45 & 36 & 9 & 0.19 \\
\hline Bus empty & 19 & 2 & 17 & $0.62^{*}$ \\
\hline Tunnel Straight & 43 & 14 & 29 & $0.66^{*}$ \\
\hline Tunnel Curve & 54 & 21 & 33 & $0.70^{*}$ \\
\hline Tunnel End & 26 & 9 & 17 & 0.46 \\
\hline Tunnel side & 45 & 21 & 24 & $0.52^{\star}$ \\
\hline Airplane altitude change & 54 & 41 & 13 & 0.25 \\
\hline Airplane altitude steady & 22 & 9 & 13 & 0.37 \\
\hline Airplane landing & 49 & 50 & -1 & -0.02 \\
\hline Airplane taking off & 48 & 48 & 0 & 0.01 \\
\hline Airplane flying smoothly & 20 & 7 & 13 & 0.38 \\
\hline Airplane flying in turbulence & 68 & 75 & -7 & -0.16 \\
\hline Airplane sitting by window & 29 & 11 & 18 & 0.45 \\
\hline Airplane sitting on aisle & 29 & 11 & 18 & 0.45 \\
\hline Airplane sitting middle seat & 39 & 31 & 8 & 0.17 \\
\hline
\end{tabular}

${ }^{*} \mathrm{p}<0.01$ 
Whitney et al, Physical Therapy and Rehabilitation 2018,

http://www.hoajonline.com/journals/pdf/2055-2386-5-18.pdf

doi: $10.7243 / 2055-2386-5-18$

Table 3. Architectural/Environmental/Activity Items: Proportion reporting being at least mildly bothered in 89 patients and 44 control subjects with group proportion differences and effect sizes $(\mathbf{h})$ of difference.

\begin{tabular}{|c|c|c|c|c|}
\hline Item & Patient (\%) & Control (\%) & Proportional Difference & $\mathbf{h}$ \\
\hline Elevator stationary & 13 & 9 & 4 & 0.12 \\
\hline Elevator Moving (vs. stationary) & 44 & 16 & 28 & $0.63^{*}$ \\
\hline Elevator crowded & 41 & 34 & 7 & 0.13 \\
\hline Elevator empty & 19 & 2 & 17 & $0.62^{*}$ \\
\hline Elevator going up & 36 & 9 & 27 & $0.68^{*}$ \\
\hline Elevator going down & 38 & 9 & 29 & $0.73^{\star}$ \\
\hline Elevator standard & 25 & 5 & 20 & $0.60^{*}$ \\
\hline Elevator glass walls & 45 & 24 & 21 & 0.45 \\
\hline Elevator start & 40 & 7 & 33 & $0.83^{\star}$ \\
\hline Elevator steady & 27 & 2 & 25 & $0.81^{*}$ \\
\hline Elevator stop & 44 & 11 & 33 & $0.77^{\star}$ \\
\hline Elevator middle & 41 & 16 & 25 & $0.57^{\star}$ \\
\hline Elevator wall & 26 & 2 & 24 & $0.79^{\star}$ \\
\hline Escalator up & 42 & 0 & 42 & $1.41^{\star}$ \\
\hline Escalator down & 43 & 5 & 38 & $0.98^{*}$ \\
\hline Escalator somebody in front & 29 & 2 & 27 & $0.85^{\star}$ \\
\hline Escalator nobody in front & 26 & 0 & 26 & $1.07^{\star}$ \\
\hline Escalator holding rail & 31 & 0 & 31 & $1.18^{\star}$ \\
\hline Escalator not holding rail & 73 & 18 & 55 & $1.17^{*}$ \\
\hline Stairways close to wall & 30 & 2 & 28 & $0.88^{*}$ \\
\hline Stairways center & 58 & 9 & 49 & $1.12^{*}$ \\
\hline Supermarket Crowded & 48 & 34 & 14 & 0.29 \\
\hline Supermarket market empty (vs. crowded) & 24 & 0 & 24 & $1.02^{*}$ \\
\hline Supermarket near exit & 18 & 0 & 18 & $0.88^{\star}$ \\
\hline Supermarket far from exit & 25 & 2 & 23 & $0.76^{*}$ \\
\hline Supermarket looking at end of aisle (while walking down aisle) & 43 & 2 & 41 & $1.15^{*}$ \\
\hline Supermarket looking at items on shelf & 58 & 7 & 51 & $1.20^{*}$ \\
\hline Walking Straight & 38 & 0 & 38 & $1.33^{*}$ \\
\hline Walking Turning & 63 & 2 & 61 & $1.55^{\star}$ \\
\hline Walking Corridor Look Straight & 44 & 2 & 42 & $1.17^{*}$ \\
\hline Walking Corridor Look Side & 73 & 9 & 64 & $1.44^{\star}$ \\
\hline Shower rinse hair & 45 & 2 & 43 & $1.19^{*}$ \\
\hline Shower wash arms & 24 & 0 & 24 & $1.02^{*}$ \\
\hline Theatre sitting in middle of row & 32 & 11 & 21 & 0.53 \\
\hline Theatre sitting on aisle & 19 & 2 & 17 & $0.62^{\star}$ \\
\hline Theatre front row & 56 & 27 & 29 & $0.60^{*}$ \\
\hline Theatre back row & 30 & 5 & 25 & $0.71^{\star}$ \\
\hline Theatre wide & 23 & 2 & 21 & $0.72^{*}$ \\
\hline Theatre narrow & 23 & 5 & 18 & 0.55 \\
\hline Field open without boundaries & 26 & 2 & 24 & $0.79^{*}$ \\
\hline Field enclosed with boundaries & 27 & 5 & 22 & $0.64^{*}$ \\
\hline Field Edge & 22 & 0 & 22 & $0.98^{\star}$ \\
\hline Field Middle & 26 & 5 & 21 & $0.62^{*}$ \\
\hline
\end{tabular}

${ }^{*} \mathrm{p}<0.01$ 
Whitney et al, Physical Therapy and Rehabilitation 2018,

http://www.hoajonline.com/journals/pdf/2055-2386-5-18.pdf

doi: $10.7243 / 2055-2386-5-18$

Table 4. Mobility/ADL Items: Proportion reporting being at least mildly bothered in 89 patients and 44 control subjects with group proportion differences and effect size (h) of difference.

\begin{tabular}{|c|c|c|c|c|}
\hline Item & Patient (\%) & Control (\%) & Proportional Difference & h \\
\hline Aerobic exercise & 66 & 2 & 64 & $1.60^{*}$ \\
\hline Rolling over in bed & 47 & 0 & 47 & $1.51^{\star}$ \\
\hline Close eyes while in shower & 76 & 11 & 65 & $1.45^{*}$ \\
\hline Look up tall buildings & 81 & 16 & 65 & $1.42^{\star}$ \\
\hline Look down from high places & 80 & 48 & 32 & $0.68^{*}$ \\
\hline Lean back in chair & 80 & 16 & 64 & $1.38^{\star}$ \\
\hline Read newspaper close & 46 & 16 & 30 & $0.67^{\star}$ \\
\hline Writing & 28 & 0 & 28 & $1.12^{*}$ \\
\hline Reach high shelf & 66 & 0 & 66 & $1.90^{*}$ \\
\hline Pick up from floor & 80 & 7 & 73 & $1.68^{\star}$ \\
\hline Look in Mirror & 15 & 0 & 15 & $0.80^{*}$ \\
\hline Merry Go Round & 80 & 21 & 59 & $1.26^{*}$ \\
\hline Roller coaster & 46 & 28 & 18 & $0.37^{\star}$ \\
\hline Dancing & 62 & 2 & 60 & $1.53^{\star}$ \\
\hline Look at Ceiling fans & 58 & 19 & 39 & $0.83^{*}$ \\
\hline Lying in bed & 15 & 0 & 15 & $0.80^{*}$ \\
\hline Putting on jacket & 19 & 2 & 17 & $0.62^{\star}$ \\
\hline Watch fast action TV & 49 & 2 & 47 & $1.27^{\star}$ \\
\hline Sitting & 11 & 0 & 11 & 0.68 \\
\hline Discomfort worsen throughout the day & 51 & 5 & 46 & $1.14^{*}$ \\
\hline
\end{tabular}

program, or picking things off the floor are activities that are often performed daily, suggesting that vestibular dysfunction affects people throughout their day. Cohen and Kimball's Vestibular ADL scale $[\mathbf{1 2}, \mathbf{1 5}]$ and the Vestibular Rehabilitation Benefit Questionnaire $[10,11]$ include two of the above five mobility items. The Vertigo Symptom Scale [13] and the Vertigo Handicap Questionnaire [14] do not include any of the above five items, whereas the Dizziness Handicap Inventory [21] includes one of the items (rolling over). Obviously, several of the ADL items on the SitQe are not currently captured with commonly used vestibular questionnaires.

Several possible explanations have been suggested to explain why people become dizzy or have increased postural sway in different visual environments. These include the background viewed, the position of the stimuli on the background, and the velocity and spatial frequency of the visual scene [22-26]. Guerraz et al [27] suggest that the symptoms in patients with vestibular disorders that are provoked in previously normal circumstances are partly due to increased visual dependence after vestibular insult. Some patients report becoming disoriented when things are perceived to be moving within their peripheral visual field $[\mathbf{1 7 , 2 8 , 2 9 ]}$.

Balance disorders have been described in persons with panic/phobic disorders [3,4,16,17,30-32]. Odman and Marie [33] suggest that the vestibular system or anxiety may be driving the space and motion discomfort often reported by patients seen in physical therapy for dizziness. They report that space and motion phobia (a pathological degree of SMD) with its associated avoidance is common in persons with "chronic subjective dizziness", which now might be called persistent postural perceptual dizziness [34-36]. The vestibular deficit augmented by anxiety tendency may produce the unusual responses that persons with vestibular disorders experience in certain daily life situations. Other authors have suggested that persons living with Méinere's disease have anxiety because of their "intolerance of uncertainty" [37]. Fear of experiencing dizziness can possibly change behavior.

The use of questionnaires that probe persons with vestibular dysfunction about their space and motion symptoms appears particularly important, as other subjective self-report measures of balance such as the Activities-specific Balance Confidence scale [38] are not sensitive to identify visual complaints associated with vestibular dysfunction [8]. It appears to be important for clinicians to be aware of functional and situational difficulties in order to design the best intervention program in order to reduce their level of disability [18].

Persons with vestibular disorders are not only affected by their dizziness and balance dysfunction but also experience discomfort in their ability to perform activities in their communities such as riding in a car and going shopping. Treating 
Whitney et al, Physical Therapy and Rehabilitation 2018,

http://www.hoajonline.com/journals/pdf/2055-2386-5-18.pdf

doi: $10.7243 / 2055-2386-5-18$

only the person's physical limitations may not be optimal. It is important to recognize that patients may present with both vestibular symptoms and discomfort at performing common activities of daily living.

Future plans for the SitQe tool include using factor analysis to determine which items are critical for identifying persons with vestibular dysfunction and to identify subtypes of discomfort, e.g., visual dependence vs. surface dependence in the control of balance. We also hope to compare the findings of the SitQe to other qualitative and quantitative physical therapy measures.

\section{Conclusion}

Patients with vestibular disorders respond differently to questions about their situationally specific SMD symptoms compared to subjects without known vestibular disorders.

\section{Competing interests}

The authors declare that they have no competing interests.

Authors' contributions

\begin{tabular}{|l|c|c|c|c|}
\hline Authors' contributions & SLW & GFM & RGJ & JMF \\
\hline Research concept and design & $\checkmark$ & $\checkmark$ & $\checkmark$ & $\checkmark$ \\
\hline Collection and/or assembly of data & $\checkmark$ & -- & -- & -- \\
\hline Data analysis and interpretation & $\checkmark$ & $\checkmark$ & $\checkmark$ & $\checkmark$ \\
\hline Writing the article & $\checkmark$ & $\checkmark$ & $\checkmark$ & $\checkmark$ \\
\hline Critical revision of the article & $\checkmark$ & $\checkmark$ & $\checkmark$ & $\checkmark$ \\
\hline Final approval of article & $\checkmark$ & $\checkmark$ & $\checkmark$ & $\checkmark$ \\
\hline Statistical analysis & -- & $\checkmark$ & -- & -- \\
\hline
\end{tabular}

Acknowledgement

The authors would like to thank Anita Lieb, MS who was helpful with the data acquisition and compliance issues with the institutional review board.

Publication history

Editor: Mohammad H. Hadadzadeh, Wheeling Jesuit University, USA. Received: 08-Sept-2018 Final Revised: 03-Nov-2018

Accepted: 07-Nov-2018 Published: 16-Nov-2018

\section{References}

1. Bronstein AM. Vision and vertigo: some visual aspects of vestibular disorders. J Neurol. 2004; 251:381-7. | Article | PubMed

2. Kroenke K, Lucas CA, Rosenberg ML and Scherokman BJ. Psychiatric disorders and functional impairment in patients with persistent dizziness. J Gen Intern Med. 1993; 8:530-5. I PubMed

3. Yardley L. Overview of psychologic effects of chronic dizziness and balance disorders. Otolaryngol Clin North Am. 2000; 33:603-16. | Article I PubMed

4. Staab JP and Ruckenstein MJ. Which comes first? Psychogenic dizziness versus otogenic anxiety. Laryngoscope. 2003; 113:1714-8. | Article | PubMed

5. Bowman A. Psychological and visual-perceptual explanations of poor compensation following unilateral vestibular loss. Sydney: The University of Sydney. 2004

6. Bronstein AM. Visual vertigo syndrome: clinical and posturography findings. J Neurol Neurosurg Psychiatry. 1995; 59:472-6. | Article | PubMed Abstract | PubMed FullText
7. Jacob RG and Furman JM. Psychiatric consequences of vestibular dysfunction. Curr Opin Neurol. 2001; 14:41-6. | Article | PubMed

8. Pavlou M, Lingeswaran A, Davies RA, Gresty MA and Bronstein AM. Simulator based rehabilitation in refractory dizziness. J Neurol. 2004; 251:983-95. | Article | PubMed

9. Jacob RG, Woody SR, Clark DB, Lilienfeld SO, Hirsch BE, Kucera GD, Furman JM and Durrant JD. Discomfort with space and motion: $A$ possible marker of vestibular dysfunction assessed by the situational characteristics questionnaire. Journal of Psychopathology and Behavioral Assessment. 1993; 15:229-324.

10. Morris AE, Lutman ME and Yardley L. Measuring outcome from Vestibular Rehabilitation, Part I: Qualitative development of a new selfreport measure. Int J Audiol. 2008; 47:169-77. | Article | PubMed

11. Morris AE, Lutman ME and Yardley L. Measuring outcome from vestibular rehabilitation, part II: refinement and validation of a new self-report measure. Int J Audiol. 2009; 48:24-37. | Article | PubMed

12. Cohen HS, Kimball KT and Adams AS. Application of the vestibular disorders activities of daily living scale. Laryngoscope. 2000; 110:1204-9. | Article | PubMed

13. Yardley L, Masson E, Verschuur C, Haacke N and Luxon L. Symptoms, anxiety and handicap in dizzy patients: development of the vertigo symptom scale. J Psychosom Res. 1992; 36:731-41. | PubMed

14. Yardley $L$ and Putman J. Quantitative analysis of factors contributing to handicap and distress in vertiginous patients: a questionnaire study. Clin Otolaryngol Allied Sci. 1992; 17:231-6. | Article | PubMed

15. Cohen HS and Kimball KT. Development of the vestibular disorders activities of daily living scale. Arch Otolaryngol Head Neck Surg. 2000; 126:881-7. | Article | PubMed

16. Jacob RG, Furman JM, Durrant JD and Turner SM. Surface dependence: a balance control strategy in panic disorder with agoraphobia. Psychosom Med. 1997; 59:323-30. | Article | PubMed

17. Jacob RG, Redfern MS and Furman JM. Space and motion discomfort and abnormal balance control in patients with anxiety disorders. J Neurol Neurosurg Psychiatry. 2009; 80:74-8. | Article | PubMed Abstract I PubMed FullText

18. Cohen J. Statistical power analysis for the behavioral sciences. Second edition edn. Hillsdale, NJ: Lawrence Erlbaum Associates 1988.

19. Page NG and Gresty MA. Motorist's vestibular disorientation syndrome. J Neurol Neurosurg Psychiatry. 1985; 48:729-35. | Article | PubMed Abstract | PubMed FullText

20. Murray KJ, Hill KD, Phillips B and Waterston J. The influence of otolith dysfunction on the clinical presentation of people with a peripheral vestibular disorder. Phys Ther. 2007; 87:143-52. | Article | PubMed

21. Jacobson GP and Newman CW. The development of the Dizziness Handicap Inventory. Arch Otolaryngol Head Neck Surg. 1990; 116:424-7. | Article | PubMed

22. Lestienne F, Soechting $J$ and Berthoz A. Postural readjustments induced by linear motion of visual scenes. Exp Brain Res. 1977; 28:363-84. | PubMed

23. Redfern MS and Furman JM. Postural sway of patients with vestibular disorders during optic flow. J Vestib Res. 1994; 4:221-30. | PubMed

24. Stoffregen TA. Flow structure versus retinal location in the optical control of stance. J Exp Psychol Hum Percept Perform. 1985; 11:554-65. | Article I PubMed

25. Borger LL, Whitney SL, Redfern MS and Furman JM. The influence of dynamic visual environments on postural sway in the elderly. J Vestib Res. 1999; 9:197-205. | Article | PubMed

26. Hoppes CW, Sparto PJ, Whitney SL, Furman JM and Huppert TJ. Functional near-infrared spectroscopy during optic flow with and without fixation. PLoS One. 2018; 13:e0193710. | Article | PubMed Abstract | PubMed FullText

27. Guerraz M, Yardley L, Bertholon P, Pollak L, Rudge P, Gresty MA and Bronstein AM. Visual vertigo: symptom assessment, spatial orientation and postural control. Brain. 2001; 124:1646-56. | PubMed 
Whitney et al, Physical Therapy and Rehabilitation 2018,

http://www.hoajonline.com/journals/pdf/2055-2386-5-18.pdf

28. Lilienfeld SO, Jacob RG and Furman JM. Vestibular dysfunction followed by panic disorder with agoraphobia. J Nerv Ment Dis. 1989; 177:700-1. I PubMed

29. Chang CP and Hain TC. A theory for treating dizziness due to optical flow (visual vertigo). Cyberpsychol Behav. 2008; 11:495-8. | Article | PubMed

30. Furman JM and Jacob RG. A clinical taxonomy of dizziness and anxiety in the otoneurological setting. J Anxiety Disord. 2001; 15:9-26. | Article PubMed

31. Redfern MS, Furman JM and Jacob RG. Visually induced postural sway in anxiety disorders. J Anxiety Disord. 2007; 21:704-16. | Article | PubMed Abstract | PubMed FullText

32. Yardley L, Britton J, Lear S, Bird J and Luxon LM. Relationship between balance system function and agoraphobic avoidance. Behav Res Ther. 1995; 33:435-9. | Article | PubMed

33. Odman $\mathrm{M}$ and Maire R. Chronic subjective dizziness. Acta Otolaryngol. 2008; 128:1085-8. | Article | PubMed

34. Popkirov S, Staab JP and Stone J. Persistent postural-perceptual dizziness (PPPD): a common, characteristic and treatable cause of chronic dizziness. Pract Neurol. 2018; 18:5-13. | Article | PubMed

35. Seemungal BM and Passamonti L. Persistent postural-perceptual dizziness: a useful new syndrome. Pract Neurol. 2018; 18:3-4. | Article | PubMed Abstract | PubMed FullText

36. Sohsten E, Bittar RS and Staab JP. Posturographic profile of patients with persistent postural-perceptual dizziness on the sensory organization test. J Vestib Res. 2016; 26:319-26. | Article | PubMed

37. Kirby SE and Yardley L. Cognitions associated with anxiety in Meniere's disease. J Psychosom Res. 2009; 66:111-8. | Article | PubMed

38. Powell LE and Myers AM. The Activities-specific Balance Confidence (ABC) Scale. J Gerontol A Biol Sci Med Sci. 1995; 50A:M28-34. | PubMed

\section{Citation:}

Whitney SL, Marchetti GF, Jacob RG and Furman JM. Measurement of space and motion discomfort in persons with vestibular disorders. Phys Ther Rehabil. 2018; 5:18. http://dx.doi.org/10.7243/2055-2386-5-18 